\title{
Emodin attenuates adenosine triphosphate-induced pancreatic ductal cell injury in vitro via the inhibition of the P2X7/NLRP3 signaling pathway
}

\author{
QINGKAI ZHANG ${ }^{1,2 *}$, FENGLIN HU $^{3 *}$, FANGYUE GUO $^{3 *}$, QI ZHOU $^{3}$, HONG XIANG $^{2}$ and DONG SHANG ${ }^{1,3}$ \\ ${ }^{1}$ Department of General Surgery, and ${ }^{2}$ Clinical Laboratory of Integrative Medicine, \\ First Affiliated Hospital of Dalian Medical University, Dalian, Liaoning 116011; \\ ${ }^{3}$ Institute (College) of Integrative Medicine, Dalian Medical University, Dalian, Liaoning 116044, P.R. China
}

Received February 13, 2019; Accepted July 9, 2019

DOI: $10.3892 /$ or.2019.7270

\begin{abstract}
Acute pancreatitis (AP) is an inflammatory disease with high morbidity and mortality rates. Pancreatic ductal cells are the most susceptible of all cell types that are exposed to the noxious stimuli of pancreatitis. Our previous studies demonstrated that emodin, a natural product extracted from Rheum palmatum L., protected pancreatic acinar cells from injutyh due to its anti-inflammatory activity. In the present study, in order to investigate the protective effects and molecular mechanisms of action of emodin on injured pancreatic ductal cells, an adenosine triphosphate (ATP)-induced model of cell injury was established using the human pancreatic ductal epithelial cell line, HPDE6-C7. The results revealed that emodin attenuated ATP-induced HPDE6-C7 cell injury by decreasing the levels of inflammatory factors, including interleukin (IL)- $1 \beta$ and IL-18. Furthermore, emodin significantly downregulated the protein levels of purinergic receptor $\mathrm{P} 2 \mathrm{X}$, ligand-gated ion channel, 7 (P2X7), NOD-like receptor protein 3 (NLRP3), apoptosis-associated speck-like protein containing a CARD (ASC) and caspase-1 in the injured HPDE6-C7 cells. The results also indicated that emodin attenuated HPDE6-C7 cell injury at least partially through the inhibition of the P2X7/NLRP3 signaling pathway. The protective effects of
\end{abstract}

Correspondence to: Professor Dong Shang, Department of General Surgery, First Affiliated Hospital of Dalian Medical University, 222 Zhongshan Road, Dalian, Liaoning 116011, P.R. China

E-mail: shangdong@dmu.edu.cn

Dr Hong Xiang, Clinical Laboratory of Integrative Medicine, First Affiliated Hospital of Dalian Medical University, Dalian, Liaoning 116011, P.R. China

E-mail: xianghong0806@163.com

*Contributed equally

Key words: pancreatic ductal cell injury, emodin, acute pancreatitis, purinergic receptor $\mathrm{P} 2 \mathrm{X}$, ligand-gated ion channel, 7, NOD-like receptor protein 3 emodin were abrogated upon pre-treatment with P2X7 overexpression plasmid, which further confirmed that the $\mathrm{P} 2 \mathrm{X} 7$ signaling pathway is the drug target of the effects of emodin against ATP-induced pancreatic ductal cell injury. Collectively, the findings of this study demonstrate that emodin attenuates ATP-induced pancreatic ductal cell injury in AP mainly through the inhibition of the P2X7/NLRP3 signaling pathway. This study suggests that emodin may be further developed for its application in future medical therapy.

\section{Introduction}

Acute pancreatitis (AP) is associated with an annual incidence ranging from 13 to 45 per 100,000 individuals in the USA (1-3). Thus, the attenuation of the increasing prevalence of AP is a major challenge in the medical field (4). In clinical situations of pancreatitis, including endoscopic retrograde pancreatography and gallstone passing, the pancreatic ductal epithelium would appear to be the most exposed to noxious stimuli (5). Pancreatic ductal epithelial cells and their secreted mucus constitute a pancreatic duct mucosal barrier, which prevents bile and trypsin from flowing back into the pancreas in a physiological state and has the barrier function of protecting pancreatic tissue from damage by internal and external substances (6). It has been reported that transient hypertension in the pancreatic duct triggers a pancreatic inflammatory cascade and destroys tight junction integrity in a mouse model $(7,8)$. The inappropriate activation of pancreatic zymogen in the pancreas results in exocrine gland parenchymal cell damage and necrosis, which eventually causes AP (9-11). Furthermore, injured pancreatic ductal cells can produce and release inflammatory factors, including interleukin (IL)-6 and IL-8 $(5,12)$. Thus, pancreatic ductal cells play critical roles in injury in AP. However, previous studies on AP have focused on pancreatic acinar cells (13-15), while studies on pancreatic ductal cells are limited (7).

Several recent studies have indicated that adenosine triphosphate (ATP), mainly released by acinar cells in the pancreas, can regulate pancreatic duct function via $\mathrm{P} 2 \mathrm{Y}$ and $\mathrm{P} 2 \mathrm{X}$ purinoceptor, and ATP-activated purinergic receptors may play important roles in pancreas pathophysiology $(16,17)$. 
The study by Hoque et al also demonstrated that ATP released from upstream pancreatic acinar cells induced the activation of inflammatory responses (18). As regards the underlying molecular mechanisms, purinergic receptor $\mathrm{P} 2 \mathrm{X}$, ligand-gated ion channel, 7 (P2X7), is a member of the P2X family of ATP-gated cation channels, and it can trigger diverse downstream signaling cascades, mainly including mitogen-activated protein kinases (MAPKs), reactive oxygen species (ROS) and nuclear factor- $\kappa \mathrm{B}$ $(\mathrm{NF}-\kappa \mathrm{B})$ transcription through coupling the ATP channels (19-23). Previous studies have demonstrated that P2X7 respectively cleaves pro-IL-1 $\beta$ and pro-IL-18 into mature IL- $1 \beta$ and IL-18 via the recruitment of the NOD-like receptor protein 3 (NLRP3) inflammasome, which is composed of NLRP3, the adaptor protein apoptosis-associated speck-like protein containing a CARD (ASC) and the effector protein caspase-1. IL-1 $\beta$ and IL-18-dependent pathways further cause pancreatic injury $(19,24)$. Thus, the ATP activated-P2X7/NLRP3 signaling pathway may be a potent therapeutic target for AP insult.

In China, Rheum palmatum L. has been utilized in the treatment of AP for a number of years as a separate or principal component in traditional formulas (e.g., Da-Cheng-Qi decoction). Emodin, also known as 1,3,8-trihydroxy-6-methylanthraquinone, is major component of Rheum palmatum L. (25). Over the past decades, significant progress has been made to evaluate the pharmacological activities of emodin in vivo and in vitro. Our previous study demonstrated that emodin exerts significant protective effects on sodium taurocholate-treated pancreatic acinar cells, although its effects on the injury of pancreatic ductal cells have not been reported to date, at least to the best of our knowledge (26). The present study evaluated the effects and potential mechanisms of action of emodin on the injury of pancreatic ductal cells in AP using an ATP-induced pancreatic ductal cell injury model.

\section{Materials and methods}

Cells and cell culture. The pancreatic human duct cell line, HPDE6-C7, was purchased from the American Type Culture Collection (ATCC). The cells were cultured in Dulbecco's modified Eagle's medium (DMEM; HyClone) supplemented with high glucose and $10 \%$ fetal bovine serum (FBS; Gibco; Thermo Fisher Scientific) at $37^{\circ} \mathrm{C}$ in a $5 \% \mathrm{CO}_{2}$ incubator.

ATP-induced cell injury. Cell viability assay using the MTT method was carried out to determine the most suitable damaging concentration of ATP (Solarbio) in vitro. In brief, HPDE6-C7 cells $\left(1 \times 10^{5}\right.$ cells $\left./ \mathrm{ml}\right)$ were treated with various concentrations of $\operatorname{ATP}(40,20,10,5,2.5$ and $1.25 \mathrm{mM})$ for $16 \mathrm{~h}$ after $24 \mathrm{~h}$ of culture in 96-well plates. Subsequently, $10 \mu \mathrm{l}$ MTT solution $(5 \mathrm{mg} / \mathrm{ml})$ were added into each well followed by $4 \mathrm{~h}$ of incubation at $37^{\circ} \mathrm{C}$. Finally, the formazan crystals were dissolved with $100 \mu \mathrm{l}$ dimethyl sulfoxide (DMSO) and measured with a microplate reader (BioTek) at a wavelength of $490 \mathrm{~nm}$.

Emodin cytotoxicity. The HPDE6-C7 cells (1x10 5 cells $/ \mathrm{ml})$ were treated with gradient concentrations of emodin $(180,90$, $45,22.5,11.25$ and $5.625 \mu \mathrm{M}$ ) (Solarbio) for $24 \mathrm{~h}$ in a humidified atmosphere of $5 \% \mathrm{CO}_{2}$ at $37^{\circ} \mathrm{C}$. Emodin was dissolved in DMSO to a final concentration of $<0.1 \%$. Finally, the MTT method was used to evaluate cell viability as described above.
Cell viability and morphology. To evaluate the effects of emodin on ATP-induced HPDE6-C7 cell injury, the cells were divided 5 five groups as follows: i) The control group; ii) ATP group; and iii) low-, iv) medium- and v) high-dose emodin groups. The cells in the control group were cultured under normal conditions without being subjected to any other treatment. The cells in the ATP group were pre-treated with $40 \mathrm{mM}$ ATP for $16 \mathrm{~h}$, while the cells in the emodin groups were respectively first treated with $11.25,22.5$ and $45 \mu \mathrm{M}$ emodin for $24 \mathrm{~h}$ prior to a $16 \mathrm{~h}$-incubation with ATP $(40 \mathrm{mM})$. Cell viability was then assessed using the aforementioned MTT method. To observe the effects of emodin on the morphology of the HPDE6-C7 cells, the cells were grown in 6-well plates and divided into 3 groups as follows: i) The control group; ii) ATP group; and iii) high-dose emodin $(45 \mu \mathrm{M})$ group. The cells were pre-treated as described above, and then imaged using a phase contrast microscope (Olympus Corp.).

Immunofluorescence detection of P2X7. Following culture in 6-well plates for $24 \mathrm{~h}$ at $37^{\circ} \mathrm{C}$, the HPDE6-C7 cells were subjected to different treatments. The cells were then fixed in $4 \%$ paraformaldehyde and incubated with diluted anti-P2X7 antibody (1:100; cat. no. ab48871; Abcam) at $4^{\circ} \mathrm{C}$ overnight. The cells were then incubated with FITC-conjugated goat anti-rabbit IgG (1:50; cat. no. SA00003-2; ProteinTech Group) for $1 \mathrm{~h}$ and re-stained with DAPI $(1 \mu \mathrm{g} / \mathrm{ml}$; ProteinTech Group) for $5 \mathrm{~min}$ in the dark at $37^{\circ} \mathrm{C}$. Immunohistochemical images (x100 magnification) were obtained using an Olympus BX63 fluorescence microscope (Olympus Corp.).

Overexpression of the P2X7 gene. The HPDE6-C7 cells $\left(1 \times 10^{5}\right.$ cells $\left./ \mathrm{ml}\right)$ were seeded into 6 -well plates for $24 \mathrm{~h}$, and then transfected with a $\mathrm{P} 2 \mathrm{X} 7$ overexpression plasmid using Lipofectamine 2000 according to the manufacturer's instructions (Thermo Fisher Scientific). The P2X7 overexpression plasmid, also termed pEX-3-P2X7 cDNA (cat. no. Y5251), was purchased from GenePharma Co., Ltd. Briefly, pEX-3-P2X7 cDNA $(2 \mu \mathrm{g})$ was diluted in $200 \mu \mathrm{l}$ of DMEM without serum, and then Lipofectamine $2000(4 \mu \mathrm{l})$ was diluted in $200 \mu \mathrm{l}$ of DMEM. Following a 5-min incubation at room temperature, the diluted DNA was combined with the diluted Lipofectamine 2000. This was followed by gentle mixing and incubation for $20 \mathrm{~min}$ at room temperature to allow the DNA-Lipofectamine 2000 complexes to form. Finally, $400 \mu \mathrm{l}$ of the complexes were added to each well, and the wells were replenished with $1.6 \mathrm{ml}$ of DMEM. Following $24 \mathrm{~h}$ of transfection, the cells were treated with emodin $(45 \mu \mathrm{M})$ and ATP (40 mM). Finally, the P2X7, NLRP3, ASC and caspase-1 protein expression levels, and the contents of IL-1 $\beta$ and IL-18 in the cell supernatant were measured by western blot analysis and ELISA, respectively.

ELISA. According to the manufacturer's instructions, the IL-1 $\beta$ and IL-18 contents in the cell supernatant were evaluated using commercially available human ELISA kits (Boster Bio). The OD values in each well were measured using a multifunctional microplate reader (BioTek) at a wavelength of $450 \mathrm{~nm}$.

Western blot assay. Total proteins from the HPDE6-C7 cells were extracted using a protein extraction kit (cat. no. KGP2100; KeyGen Biotech), and the protein 


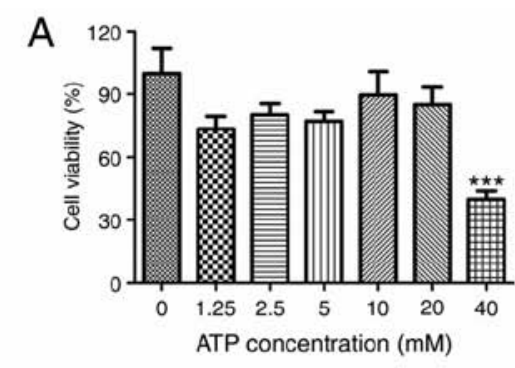

D

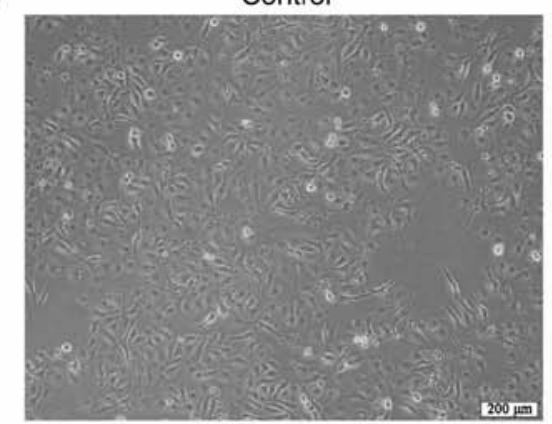

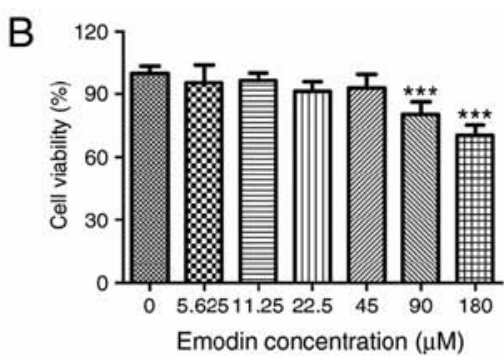

ATP

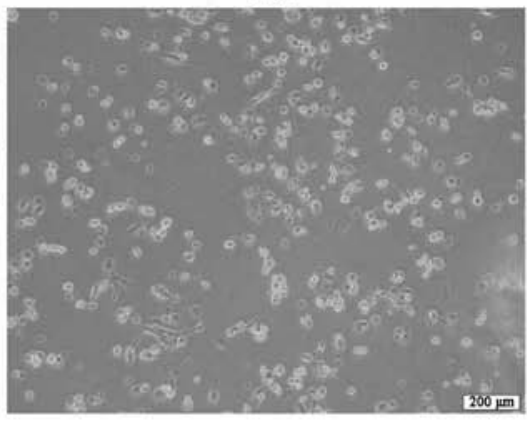

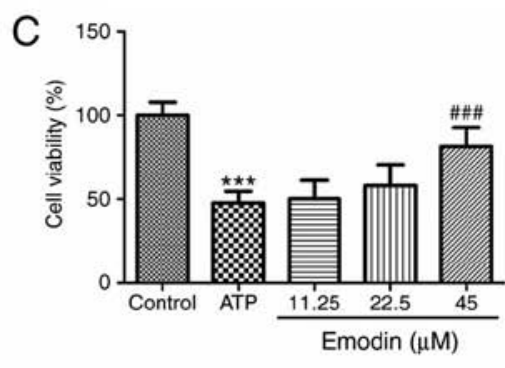

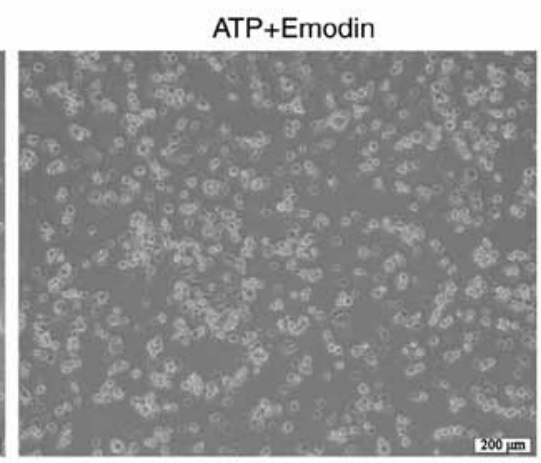

Figure 1. Emodin attenuates ATP-induced HPDE6-C7 cell injury. (A) Effects of various concentrations doses of ATP (1.25, 2.5, 5, 10, 20 and 40 mM) on HPDE6-C7 cell viability following $16 \mathrm{~h}$ of pre treatment. (B) Cytotoxicity of emodin $(5.625,11.25,22.5,45$ and $90 \mu \mathrm{M})$ on HPDE6-C7 cells following $24 \mathrm{~h}$ of pre-treatment. (C) Effects of emodin (11.25, 22.5 and $45 \mu \mathrm{M})$ on the viability of ATP (40 mM)-treated HPDE6-C7 cells. (D) Representative images of HPDE6-C7 cell morphology in the different groups (magnification, $\mathrm{x} 100)$; ATP, $40 \mathrm{mM}$; emodin, $45 \mu \mathrm{M}$ ( $\mathrm{n}=6$; ' $\mathrm{n}$ ' refers to the number of samples). ${ }^{* * *} \mathrm{P}<0.001$ vs. control group, ${ }^{\# \#} \mathrm{P}<0.001$ vs. ATP group. ATP, adenosine triphosphate.

concentrations were determined using a BCA protein assay kit (cat. no. KGP902; KeyGen Biotech). Protein samples were separated by SDS-PAGE (10-12\%) and then transferred onto PVDF membranes (EMD Millipore). The membranes were then blocked and incubated with primary antibodies against P2X7 (cat. no. ab48871), NLRP3 (cat. no. ab214185), ASC (cat. no. ab155970) and caspase-1 (cat. no. ab1872) (all from Abcam and 1:800 dilution in TBST) overnight at $4^{\circ} \mathrm{C}$. Following incubation with the secondary antibody [cat. no. SA00001-2; HRP-conjugated Affinipure goat anti-rabbit IgG $(\mathrm{H}+\mathrm{L})$ ProteinTech Group] (1:2,000 dilution in TBST) at room temperature for $2 \mathrm{~h}$, the protein expression in the membranes was visualized by enhanced ECL using Tanon-5200 Multi Gel Imaging System (Tanon Science and Technology). $\beta$-actin (cat. no. ab179467; Abcam) was used as the internal control. Quantitative analysis was performed using Gel-Pro analyzer 4.0 software (Media Cybernetics).

Statistical analysis. Data are expressed as the means \pm standard deviation (SD) and analyzed using SPSS 17.0 software (SPSS, Inc.). Differences between multiple groups were analyzed using one-way analysis of variance with Tukey's post-hoc test. Comparisons between 2 groups were made using an unpaired Student's t-test. A value of $\mathrm{P}<0.05$ was considered to indicate a statistically significant difference.

\section{Results}

Emodin attenuates ATP-induced HPDE6-C7 cell injury. In order to establish a model of ATP-induced injury using normal human pancreatic ductal epithelial cells, we adopted various concentrations of ATP to stimulate the HPDE6-C7 cells. As shown in Fig. 1A, ATP at a concentration of $40 \mathrm{mM}$ significantly decreased the viability of the HPDE6-C7 cells. Thus, $40 \mathrm{mM}$ was selected as the stimulus dose for the in vitro model in the subsequent experiments. Furthermore, to identify the safe concentration of emodin, the cytotoxicity of emodin against the HPDE6-C7 cells was evaluated by MTT assay. As shown in Fig. 1B, the results indicated that treatment with $90 \mu \mathrm{M}$ emodin exerted marked cellular cytotoxicity $(\mathrm{P}<0.001)$, which demonstrated that $45 \mu \mathrm{M}$ was the maximum safe concentration of emodin. In addition, as shown in Fig. 1C, emodin $(45 \mu \mathrm{M})$ notably increased cell viability compared with the ATP model group. Furthermore, the cell morphology images presented in Fig. 1D indicated that ATP significantly induced HPDE6-C7 cell death, and that this was attenuated by emodin $(45 \mu \mathrm{M})$. Therefore, these results suggested that emodin exerted a potent protective effect against ATP-induced HPDE6-C7 cell injury.

Emodin suppresses the expression of proteins associated with the P2X7/NLRP3 signaling pathway in ATP-stimulated HPDE6-C7 cells. In order to examine the effects of emodin on $\mathrm{P} 2 \mathrm{X} 7$ protein expression, we performed a $\mathrm{P} 2 \mathrm{X} 7$ immunofluorescence assay. As shown in Figs. 2 and $\mathrm{S} 1$, the number of P2X7-positive cells exhibiting green fluorescence was significantly increased in the ATP group; however, treatment with emodin $(45 \mu \mathrm{M})$ markedly decreased this green fluorescence. Subsequently, we evaluated whether the P2X7/NLRP3 signaling pathway is involved in the protective effects of emodin against ATP-induced HPDE6-C7 cell injury. The results shown in Fig. 3 revealed that the expression of proteins associated with the P2X7/NLRP3 signaling pathway, 

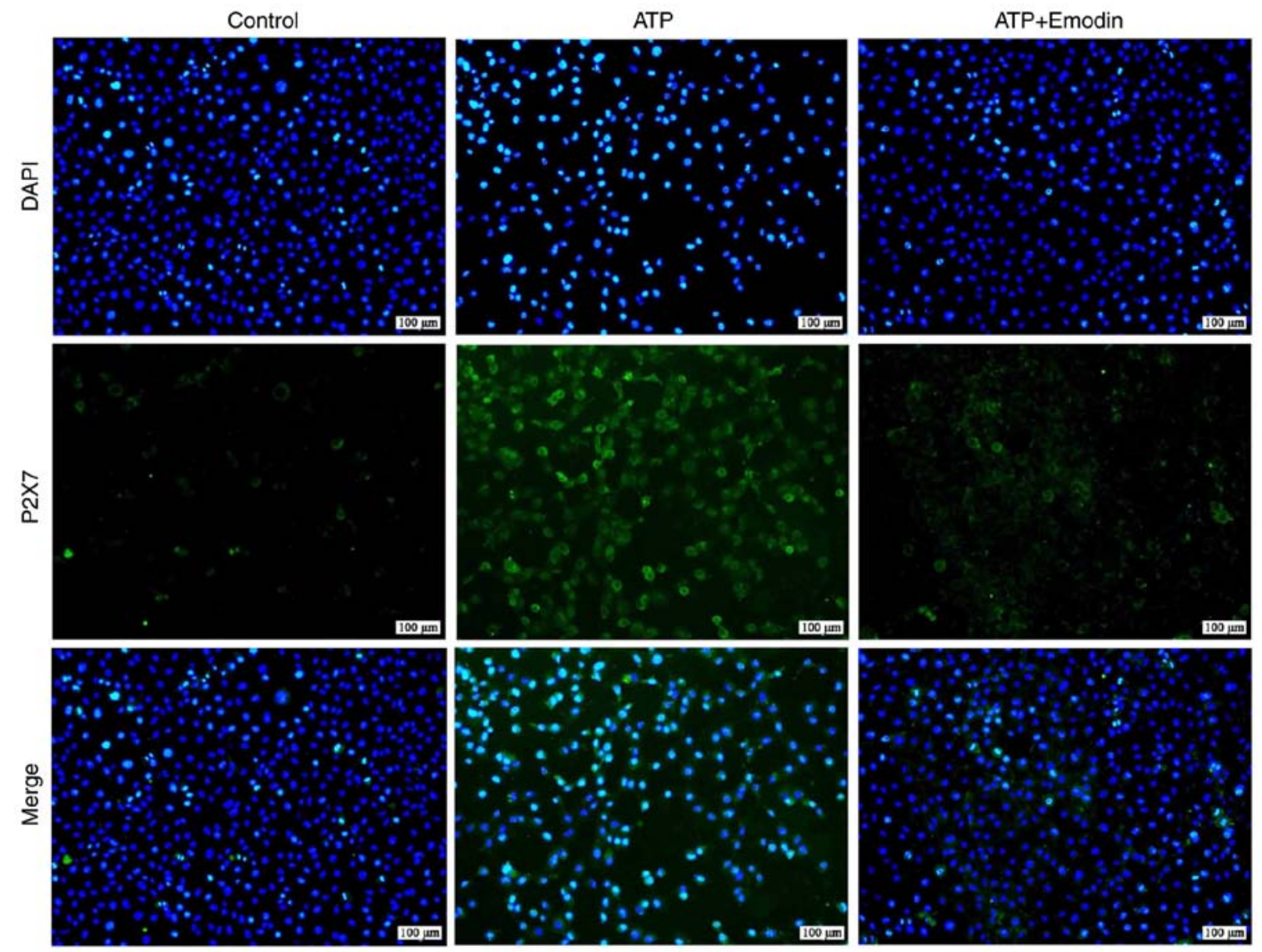

Figure 2. Emodin $(45 \mu \mathrm{M})$ downregulates P2X7 protein expression in ATP-treated HPDE6-C7 cells based on the results of an immunofluorescence assay (magnification, x200). P2X7, purinergic receptor P2X, ligand-gated ion channel, 7.
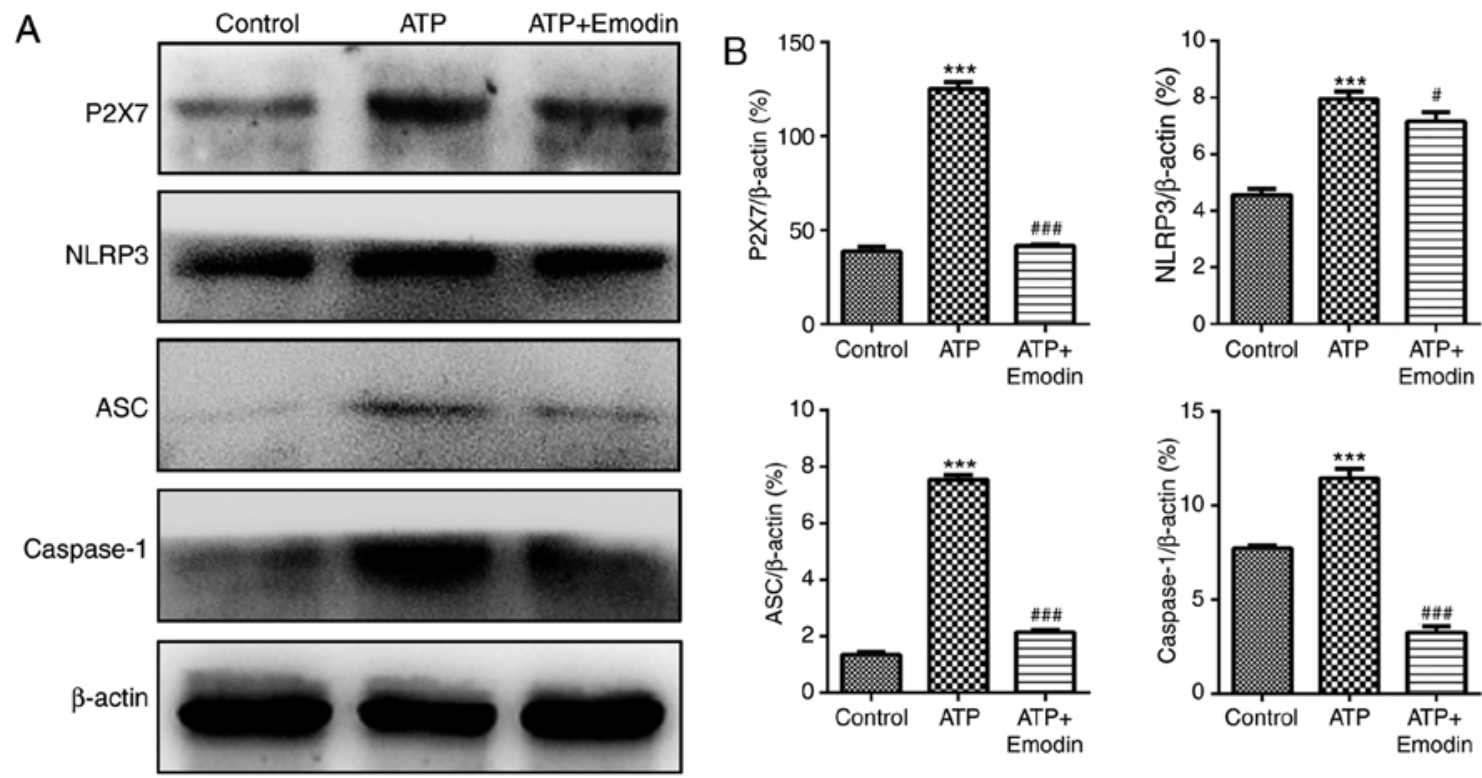

Figure 3. Emodin inhibits the expression of proteins associated with the P2X7/NLRP3 signaling pathway in ATP-stimulated HPDE6-C7 cells. (A) Effects of emodin $(45 \mu \mathrm{M})$ on the protein expression of P2X7, NLRP3, ASC and caspase-1 in ATP-stimulated HPDE6-C7 cells. (B) Statistical analysis of the effects of emodin on protein expression ( $\mathrm{n}=3$; ' $\mathrm{n}$ ' refers to the number of repeats). ${ }^{* * *} \mathrm{P}<0.001$ vs. control group, ${ }^{\#} \mathrm{P}<0.05$ vs. ATP group, ${ }^{\# \# "} \mathrm{P}<0.001$ vs. ATP group. ATP, adenosine triphosphate; P2X7, purinergic receptor P2X, ligand-gated ion channel, 7; NLRP3, NOD-like receptor protein 3; ASC, apoptosis-associated speck-like protein containing a CARD.

including P2X7, NLRP3, ASC and caspase-1 in the ATP group was significantly increased compared with the control group.
Treatment with emodin $(45 \mu \mathrm{M})$ markedly inhibited the levels of these proteins. Therefore, emodin can attenuate HPDE6-C7 

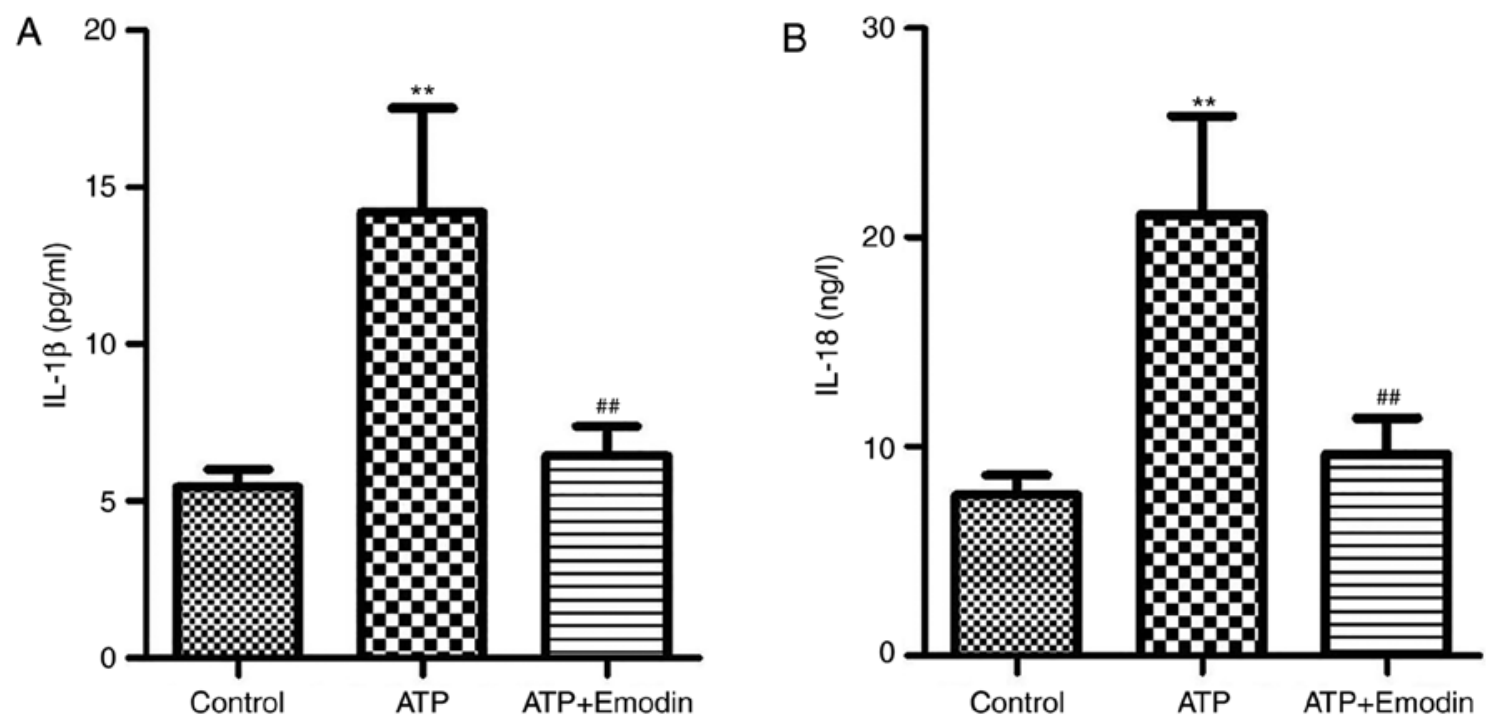

Figure 4. Emodin reduces the contents of (A) IL-1 $\beta$ and (B) IL-18 in the cell supernatant ( $n=6$; ' $n$ ' refers to the number of samples). ${ }^{* *} \mathrm{P}<0.01$ vs. control group, ${ }^{\# \#} \mathrm{P}<0.01$ vs. ATP group. ATP, adenosine triphosphate; IL, interleukin.

\section{A P2X7-CDNA}

$$
\text { P2X7 }
$$
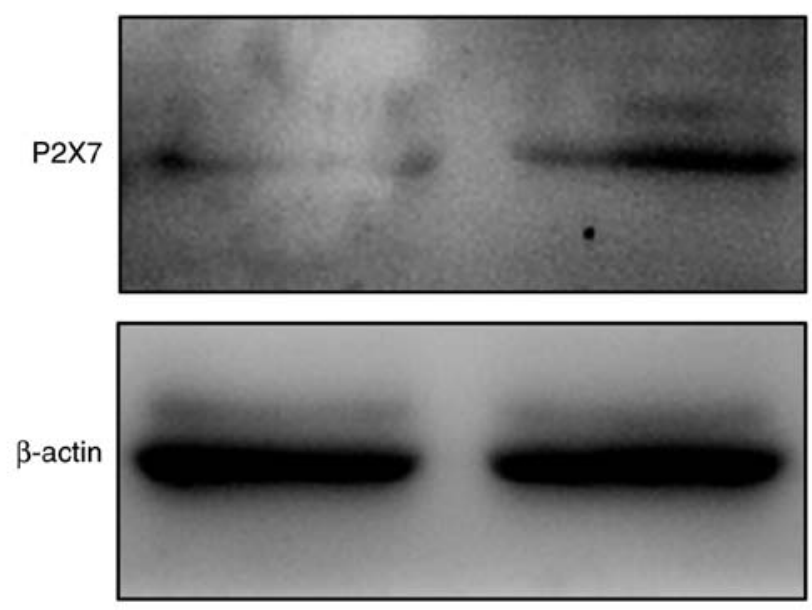

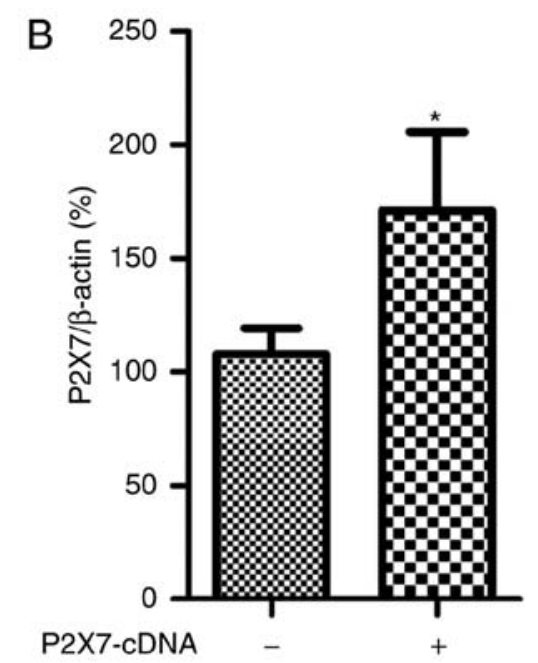

Figure 5. P2X7 expression is significantly increased following transfection with a P2X7 plasmid (pEX-3-P2X7 cDNA). (A) Effects of P2X7 overexpression on the protein expression of $\mathrm{P} 2 \mathrm{X} 7$ in HPDE6-C7 cells. (B) Statistical analysis of $\mathrm{P} 2 \mathrm{X} 7$ protein expression ( $\mathrm{n}=3$; ' $\mathrm{n}$ ' refers to the number of repeats). "P $<0.05$ vs. negative control group. $\mathrm{P} 2 \mathrm{X} 7$, purinergic receptor $\mathrm{P} 2 \mathrm{X}$, ligand-gated ion channel, 7.

cell injury induced by ATP through the inhibition of the P2X7/NLRP3 signaling pathway.

Emodin reduces the contents of $I L-1 \beta$ and $I L-18$ in the supernatant of ATP-stimulated HPDE6-C7 cells. The present study examined the effects of emodin on the conents of IL-1 $\beta$ and IL-18 in ATP-stimulated HPDE6-C7 cells. The results shown in Fig. 4 indicated that the contents of IL-1 $\beta$ and IL-18 in the cell supernatant were significantly increased in the model group, and that these effects were reversed by treatment with emodin $(45 \mu \mathrm{M})$.

Overexpression of $P 2 X 7$ abrogates the protective effects of emodin on ATP-stimulated HPDE6-C7 cells. In order to explore the role of $\mathrm{P} 2 \mathrm{X} 7$ on the protective effects of emodin against ATP-induced HPDE6-C7 cell injury, a P2X7-cDNA plasmid was used to overexpress the $\mathrm{P} 2 \mathrm{X} 7$ gene. As shown in Fig. 5, the protein level of P2X7 was notably increased following transfection with the $\mathrm{P} 2 \mathrm{X} 7$ plasmid compared with the negative control group. Furthermore, as shown in Figs. 6 and S2, the morphological damage and the number of $\mathrm{P} 2 \mathrm{X} 7$-positive cells in the $\mathrm{P} 2 \mathrm{X} 7$ overexpression group were significantly increased compared with the negative control group. However, these effects were not attenuated by treatment with emodin $(45 \mu \mathrm{M})$. Therefore, $\mathrm{P} 2 \mathrm{X} 7$ overexpression reversed the protective effects of emodin against ATP-induced HPDE6-C7 cell injury.

In addition, as shown in Fig. 7, following transfection with the $\mathrm{P} 2 \mathrm{X} 7$ overexpression plasmid, regardless of the presence of emodin, the expression levels of P2X7, NLRP3, ASC and caspase-1 were all notably upregulated compared with the control group. In addition, as shown in Fig. 8, similar results were also observed regarding the release of IL- $1 \beta$ and IL-18 in the cell supernatant. Overall, these results suggested that P2X7 


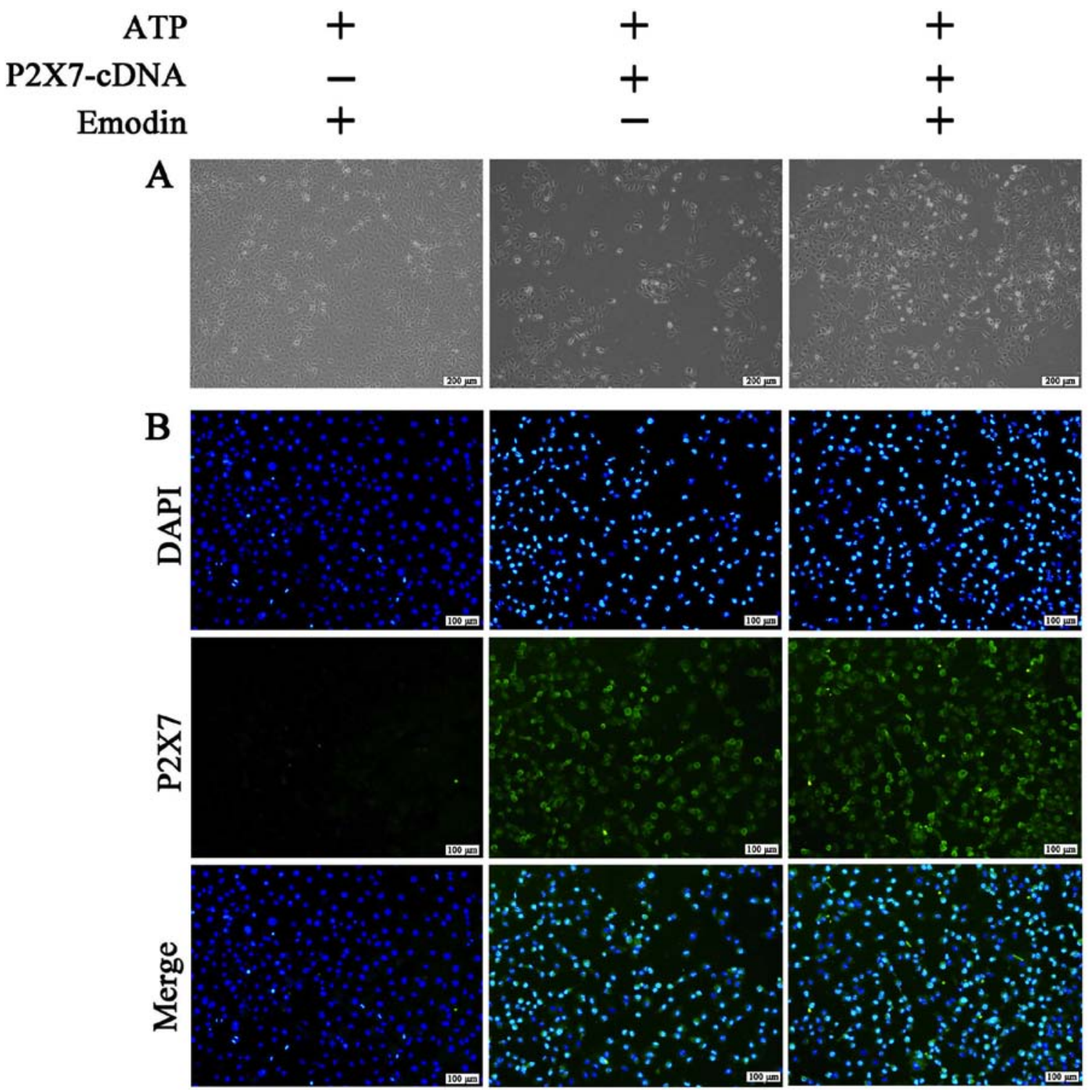

Figure 6. The protective effects of emodin on ATP-injured HPDE6-C7 cells are abrogated by P2X7 overexpression performed by transfection with pEX-3-P2X7 cDNA. (A) Effects of emodin and P2X7 overexpression on the morphology of HPDE6-C7 cells (magnification, x100). (B) Effects of emodin and P2X7 overexpression on P2X7 protein expression based on the results of an immunofluorescence assay (magnification, x200). ATP, adenosine triphosphate; P2X7, purinergic receptor $\mathrm{P} 2 \mathrm{X}$, ligand-gated ion channel, 7.

overexpression abrogated the regulation of the P2X7/NLRP3 signaling pathway mediated by emodin, which further demonstrated that the protective actions of emodin on ATP-induced pancreatic ductal cell injury were mainly due to the inhibition of the P2X7/NLRP3 signaling pathway.

\section{Discussion}

The pancreatic duct is mainly formed by epithelial cells, since it is linked by centro-acinar cells interfaced with pancreatic acini at the terminal end (27). A previous study reported that pancreatic acini can release ATP into the ductal lumen in response to various stimuli, thus activating $\mathrm{P} 2 \mathrm{Y}$ and $\mathrm{P} 2 \mathrm{X}$ receptors to regulate the epithelial secretion of the pancreatic duct (28). Ductal occlusion and injury have been postulated to lead to focal pancreatic inflammation, and the time of ductal occlusion determines the severity of AP. Thus, the present study established a model of ATP-induced injury using normal human pancreatic ductal epithelial cells (HPDE6-C7) and revealed that ATP at a concentration of $40 \mathrm{mM}$ markedly decreased cell viability. Furthermore, to examine the protective effects of emodin against ATP-induced HPDE6-C7 cell injury, the cytotoxicity of emodin on HPDE6-C7 cells was evaluated, and it was observed that $45 \mu \mathrm{M}$ was the maximum safe concentration for emodin. Emodin at this safe concentration markedly increased cell viability, and attenuated the adverse morphological changes in the HPDE6-C7 cells stimulated with ATP. Therefore, the results of the present study indicated that emodin exerted a potent effect against ATP-induced pancreatic ductal epithelial cell injury.

$\mathrm{P} 2 \mathrm{X} 7$ is primarily expressed in rodent duct cells in the pancreas and is a member of the $\mathrm{P} 2 \mathrm{X}$ family of ATP-gated cation channels $(29,30)$. The activation of P2X7 can effectively stimulate NLRP3, which is a member of the NOD-like receptor family, and can respond to a series of intrinsic stimuli and external stress signals (31). Activated NLRP3 protein can 

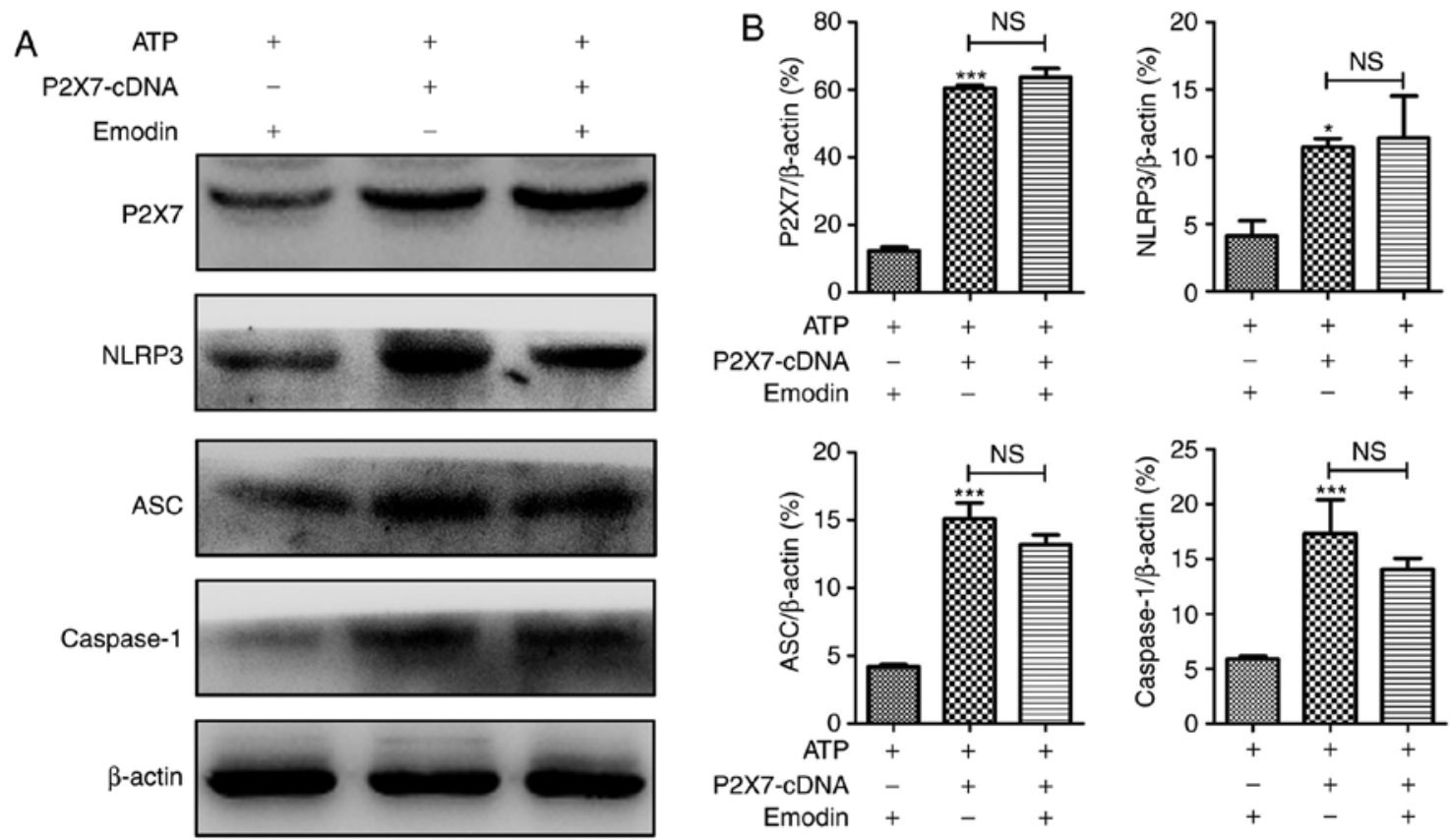

Figure 7. The inhibitory effects of emodin on the P2X7/NLRP3 pathway are abrogated by P2X7 overexpression performed by transfection with pEX-3-P2X7 cDNA. (A) Effects of emodin and P2X7 overexpression on P2X7, NLRP3, ASC and caspase-1 expression levels in adenosine triphosphate-treated HPDE6-C7 cells based on the results of western blot analysis. (B) Statistical analysis of the effects of emodin and P2X7 overexpression on protein expressions levels (n=3; ' $\mathrm{n}$ ' refers to the number of repeats). ${ }^{*} \mathrm{P}<0.05$ vs. control group, ${ }^{* * * *} \mathrm{P}<0.001$ vs. control group, NS, not significant; ATP, adenosine triphosphate; $\mathrm{P} 2 \mathrm{X} 7$, purinergic receptor P2X, ligand-gated ion channel, 7; NLRP3, NOD-like receptor protein 3; ASC, apoptosis-associated speck-like protein containing a CARD.
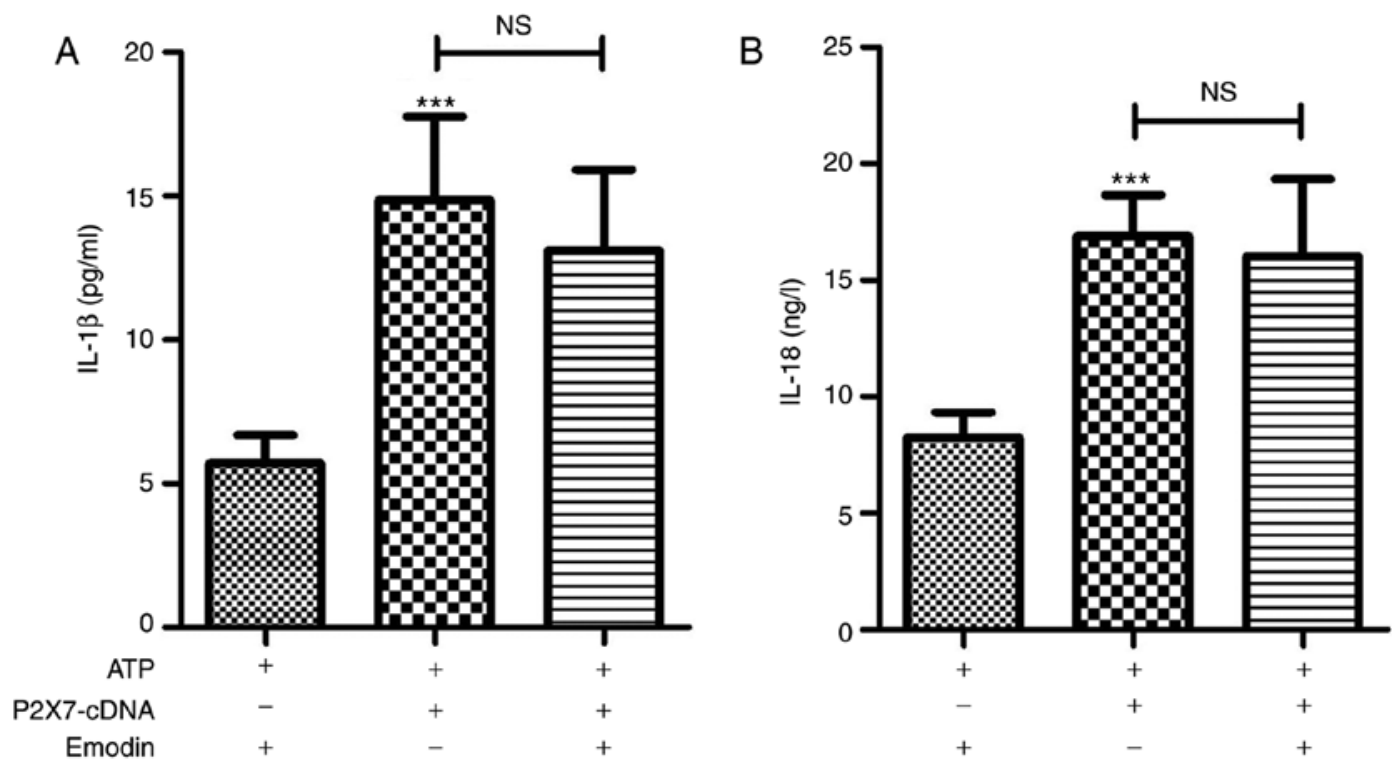

Figure 8. The inhibitory effects of emodin on (A) IL-1 $\beta$ and (B) IL-18 in the cell supernatant are abrogated by P2X7 overexpression performed by pEX-3-P2X7 cDNA based on the results of ELISA ( $\mathrm{n}=6 ; \mathrm{n}$ ' refers to the number of samples). ${ }^{* * *} \mathrm{P}<0.001$ vs. control group, NS, not significant; $\mathrm{P} 2 \mathrm{X} 7$, purinergic receptor $\mathrm{P} 2 \mathrm{X}$, ligand-gated ion channel, 7; IL, interleukin.

recruit ASC and caspase-1 proteins to form the NLRP3 inflammasome. The activated NLRP3 inflammasome promotes the caspase-1-dependent cleavage of pro-IL-1 $\beta$ and pro-IL-18 into active IL-1 $\beta$ and IL-18, respectively, and increases their subsequent release from the cell (32). The study by Hoque et al reported that the genetic deletion of Nlrp3 reduced pro-IL-1 $\beta$ expression, inflammatory responses and pancreatic edema in caerulein-induced pancreatitis (18). Therefore, the ATP-dependent P2X7/NLRP3 signaling pathway may be a potent therapeutic target for pancreatic ductal epithelial cell injury in AP. The present study detected the expression levels of the proteins involved in the P2X7/NLRP3 signaling pathway, and observed that emodin markedly downregulated the protein expression of P2X7, NLRP3, ASC and caspase-1.

Mature IL-1 $\beta$ can modify and activate pro-inflammatory cytokines, including IL- 8 , IL-17 and tumor necrosis factor- $\alpha$ by binding to IL-1 $\beta$ receptors. Thus, IL-1 $\beta$ is an early and potent pro-inflammatory factor in response to infections and tissue 
damage (33,34). IL-18 has a similar structure and function to IL-1 $\beta$, and plays an important role in regulating innate immunity and inflammation in multiple inflammatory diseases, thus acting as a novel pro-inflammatory cytokine (24). The findings of this study demonstrated that emodin notably decreased the levels of IL-1 $\beta$ and IL-18.

In addition, in this study, $\mathrm{P} 2 \mathrm{X} 7$ overexpression by the $\mathrm{P} 2 \mathrm{X} 7$ plasmid abrogated the protective effects of emodin on pancreatic ductal cells and its inhibition of the P2X7/NLRP3 signaling pathway. Therefore, $\mathrm{P} 2 \mathrm{X} 7$ may be a drug target of emodin against ATP-induced pancreatic ductal cell injury. These results further confirmed that emodin exerts potent effects against ATP-induced pancreatic ductal cell injury by inhibiting the P2X7/NLRP3 signaling pathway and the subsequent inflammatory reaction.

In conclusion, $\mathrm{P} 2 \mathrm{X} 7$ acts as a potent drug target of emodin for preventing the spontaneous activation of ATP-dependent P2X7/NLRP3 signaling, which has important implications in pancreatic ductal cell injury in AP pathologies. These findings may contribute to further advancements in the development of emodin for medical interventions in patients with AP.

\section{Acknowledgements}

Not applicable.

\section{Funding}

This study was supported by the Key Project Supported by Clinical Ability Construction of Liaoning Province (No. LNCCC-A03-2015) and the National Natural Science Foundation of China (No. 81873156).

\section{Availability of data and materials}

The datasets used and/or analyzed during the present study are available from the corresponding author on reasonable request.

\section{Authors' contributions}

HX and DS conceived and designed the experiments, and drafted the manuscript. QZhang, FH, and FG performed the cell culture experiments and gene transfection experiments. QZhang and FH performed the western blot analyses, and QZhou performed the ELISA. All authors have read and approved the final manuscript.

\section{Ethics approval and consent to participate}

Not applicable.

\section{Patient consent for publication}

Not applicable.

\section{Competing interests}

The authors declare that they have no competing interests.

\section{References}

1. Lankisch PG, Apte M and Banks PA: Acute pancreatitis. Lancet 386: 85-96, 2015.

2. Manohar M, Verma AK, Venkateshaiah SU, Sanders NL and Mishra A: Pathogenic mechanisms of pancreatitis. World J Gastrointest Pharmacol Ther 8: 10-25, 2017.

3. O'Reilly DA and Kingsnorth AN: A brief history of pancreatitis. J R Soc Med 94: 130-132, 2001.

4. Zhou Q, Xia S, Guo F, Hu F, Wang Z, Ni Y, Wei T, Xiang H and Shang D: Transforming growth factor- $\beta$ in pancreatic diseases: Mechanisms and therapeutic potential. Pharmacol Res 142: 58-69, 2019.

5. Blanchard JN II, Barve S, Joshi-Barve S, Talwalker R and Gates LK Jr: Cytokine production by CAPAN-1 and CAPAN-2 cell lines. Dig Dis Sci 45: 927-932, 2000.

6. Neoptolemos JP, London NJ and Carr-Locke DL: Assessment of main pancreatic duct integrity by endoscopic retrograde pancreatography in patients with acute pancreatitis. Br J Surg 80: 94-99, 1993.

7. Wen L, Javed TA, Yimlamai D, Mukherjee A, Xiao X and Husain SZ: Transient high pressure in pancreatic ducts promotes inflammation and alters tight junctions via calcineurin signaling in mice. Gastroenterology 155: 1250-1263.e5, 2018.

8. Venglovecz V, Rakonczay Z Jr, Gray MA and Hegyi P: Potassium channels in pancreatic duct epithelial cells: Their role, function and pathophysiological relevance. Pflugers Arch 467: 625-640, 2015.

9. Xiang H, Zhang QK, Qi B, Tao XF, Xia SL, Song HY, Qu JL and Shang D: Chinese herbal medicines attenuate acute pancreatitis: Pharmacological activities and mechanisms. Front Pharmacol 8: 216, 2017.

10. Hegyi P and Petersen $\mathrm{OH}$ : The exocrine pancreas: The acinar-ductal tango in physiology and pathophysiology. Rev Physiol Biochem Pharmacol 165: 1-30, 2013.

11. Novak I, Haanes KA and Wang J: Acid-base transport in pancreas-new challenges. Front Physiol 4: 380, 2013.

12. Blanchard JN II, Blanchard JA, Barve S, Joshi-Barve S, Talwalker R and Gates LK Jr: Antioxidants inhibit cytokine production and suppress NF-kappaB activation in CAPAN-1 and CAPAN-2 cell lines. Dig Dis Sci 46: 2768-2772, 2001.

13. Wen L, Voronina S, Javed MA, Awais M, Szatmary P, Latawiec D, Chvanov M, Collier D, Huang W, Barrett J, et al: Inhibitors of ORAI1 prevent cytosolic calcium-associated injury of human pancreatic acinar cells and acute pancreatitis in 3 mouse models. Gastroenterology 149: 481-492.e7, 2015.

14. Mrazek AA, Bhatia V, Falzon M, Spratt H, Chao C and Hellmich MR: Apigenin decreases acinar cell damage in pancreatitis. Pancreas 48: 711-718, 2019.

15. Kong L, Wu Q, Zhao L, Ye J, Li N and Yang H: Effect of microRNA-27a-5p on apoptosis and inflammatory response of pancreatic acinar cells in acute pancreatitis by targeting PTEN. J Cell Biochem 120: 15844-15850, 2019

16. Novak I, Jans IM and Wohlfahrt L: Effect of P2X(7) receptor knockout on exocrine secretion of pancreas, salivary glands and lacrimal glands. J Physiol 588: 3615-3627, 2010.

17. Henriksen KL and Novak I: Effect of ATP on intracellular $\mathrm{pH}$ in pancreatic ducts involves $\mathrm{P} 2 \mathrm{X} 7$ receptors. Cell Physiol Biochem 13: 93-102, 2003.

18. Hoque R, Sohail M, Malik A, Sarwar S, Luo Y, Shah A, Barrat F, Flavell R, Gorelick F, Husain S and Mehal W: TLR9 and the NLRP3 inflammasome link acinar cell death with inflammation in acute pancreatitis. Gastroenterology 141: 358-369, 2011.

19. Giuliani AL, Sarti AC, Falzoni S and Di Virgilio F: The P2X7 receptor-interleukin-1 liaison. Front Pharmacol 8: 123, 2017.

20. Sanz JM, Chiozzi P, Ferrari D, Colaianna M, Idzko M, Falzoni S, Fellin R, Trabace L and Di Virgilio F: Activation of microglia by amyloid \{beta\} requires $\mathrm{P} 2 \mathrm{X} 7$ receptor expression. J Immunol 182: 4378-4385, 2009.

21. Zhu S, Wang Y, Wang X, Li J and Hu F: Emodin inhibits ATP-induced IL-1 $\beta$ secretion, ROS production and phagocytosis attenuation in rat peritoneal macrophages via antagonizing $\mathrm{P}_{2} \mathrm{X}_{7}$ receptor. Pharm Biol 52: 51-57, 2014.

22. Xu H, Xiong C, He L, Wu B, Peng L, Cheng Y, Jiang F, Tan L, Tang L, Tu Y, et al: Trans-resveratrol attenuates high fatty acid-induced $\mathrm{P} 2 \mathrm{X} 7$ receptor expression and IL-6 release in PC12 cells: Possible role of P38 MAPK pathway. Inflammation 38: 327-337, 2015. 
23. Chen Q, Wu H, Qin S, Liu C, Chen Y, Yang Y and Xu C: The $\mathrm{P} 2 \mathrm{X} 7$ receptor involved in gp120-induced cell injury in BV2 microglia. Inflammation 39: 1814-1826, 2016.

24. Yuan BS, Zhu RM, Braddock M, Zhang XH, Shi W and Zheng MH: Interleukin-18: A pro-inflammatory cytokine that plays an important role in acute pancreatitis. Expert Opin Ther Targets 11: 1261-1271, 2007.

25. Dong X, Fu J, Yin X, Cao S, Li X, Lin L and Huyiligeqi Ni J: Emodin: A review of its pharmacology, toxicity and pharmacokinetics. Phytother Res 30: 1207-1218, 2016.

26. Xiang H, Tao X, Xia S, Qu J, Song H, Liu J and Shang D: Emodin alleviates sodium taurocholate-induced pancreatic acinar cell injury via MicroRNA-30a-5p-mediated inhibition of high-temperature requirement a/transforming growth factor beta 1 inflammatory signaling. Front Immunol 8: 1488, 2017.

27. Zhou Q and Melton DA: Pancreas regeneration. Nature 557: 351-358, 2018.

28. Kowal JM, Yegutkin GG and Novak I: ATP release, generation and hydrolysis in exocrine pancreatic duct cells. Purinergic Signal 11: 533-550, 2015.
29. Novak I, Nitschke R and Amstrup J: Purinergic receptors have different effects in rat exocrine pancreas. Calcium signals monitored by fura- 2 using confocal microscopy. Cell Physiol Biochem 12: 83-92, 2002.

30. Burnstock $G$ and Novak I: Purinergic signalling in the pancreas in health and disease. J Endocrinol 213: 123-141, 2012.

31. Yan Y, Jiang W, Liu L, Wang X, Ding C, Tian Z and Zhou R: Dopamine controls systemic inflammation through inhibition of NLRP3 inflammasome. Cell 160: 62-73, 2015.

32. Li X and Zhong F: Nickel induces interleukin-1 $\beta$ secretion via the NLRP3-ASC-caspase-1 pathway. Inflammation 37: 457-466, 2014.

33. de Torre-Minguela C, Mesa Del Castillo P and Pelegrin P: The NLRP3 and pyrin inflammasomes: Implications in the pathophysiology of autoinflammatory diseases. Front Immunol 8: 43, 2017.

34. Wen H, Miao EA and Ting JP: Mechanisms of NOD-like receptor-associated inflammasome activation. Immunity 39: 432-441, 2013 